\title{
Questes
}

Revue pluridisciplinaire d'études médiévales

$4 \mid 2003$

L'arbre

\section{Les arbres dans la tradition visionnaire : deux exemples particuliers}

\section{Mattia Cavagna}

\section{(2) OpenEdition}

1 Journals

\section{Édition électronique}

URL : http://journals.openedition.org/questes/1739

DOI : 10.4000/questes. 1739

ISSN : 2109-9472

\section{Éditeur}

Les Amis de Questes

\section{Édition imprimée}

Date de publication : 15 mai 2003

Pagination : 11-12

ISSN : 2102-7188

\section{Référence électronique}

Mattia Cavagna, «Les arbres dans la tradition visionnaire : deux exemples particuliers », Questes [En ligne], 4 | 2003, mis en ligne le 01 janvier 2014, consulté le 15 septembre 2020. URL : http:// journals.openedition.org/questes/1739

\section{(c) Association des amis de «Questes »}




\section{Les arbres dans la tradition visionnaire : deux exemples particuliers}

\section{Mattia CAVAGNA}

Les représentations du Paradis proposées par les récits visionnaires sont toujours calquées sur l'image du jardin d'Eden, avec pour conséquence la présence de l'arbre de la science du Bien et du Mal et d'une quantité d'autres arbres fruitiers, symbole de la Nature parfaite du Paradis. À côté de la traditionnelle végétation paradisiaque, deux exemples d'arbres occupent une place très particulière.

Le premier est décrit par la Vision de Godescalcus, un texte du XII siècle. Ravi en extase par deux anges, le moine Godescalcus se retrouve sur un chemin qui mène à un champ tout couvert d'épines. Au bord de ce champ se trouve un tilleul aux branches duquel pendent des paires de souliers ; sur l'arbre, un ange distribue les chaussures aux âmes des justes, alors que celles des pécheurs doivent passer les pieds nus. Le texte consacre un paragraphe entier à la description de cet ange (De angelo calciamenta distribuente) qui est conduite avec une vivacité tout à fait remarquable :

... il les distribuait non pas sur demande (non postulatus), non pas à toutes les âmes ensemble ni en même temps (non simul nec in uno loco), mais à chacun à leur tour; et il allait prendre les souliers avec une grande agilité (mira agilitate) tantôt en montant, tantôt en descendant sur les branches les plus éloignées.

Dans ce premier texte, l' «arbre aux souliers» est placé dans un espace intermédiaire, n'appartenant ni à l'Enfer ni au Paradis. Sa connotation reste, en tout cas, tout à fait positive : les souliers sont en quelque sorte les fruits de l'arbre destinés aux justes. 
L'autre exemple est propre à la tradition islamique. Dans trois passages du Coran on retrouve un arbre (nommé az-Zoqqum) qui est situé au parfond de l'Enfer et dont les fruits sont destinés aux damnés (Cor. 37, 60 ; 44, 43 ; 56, 52). Un texte fondamental, qui transmet cette croyance au Moyen Age occidental est le Speculum Historiale de Vincent de Beauvais. Au livre XXIII il évoque les origines historiques de l'Islam et aux chapitres 65-67 il relate la Vision de Mahomet, tirée du Coran. En voici un passage extrait de la traduction réalisée en 1330 par Jehan de Vignay (Vision de Mahomet, tirée du Miroir Histoiral ; ms. BNF fr. 310, fol. 314 a. En cours d'édition) :

L'arbre de Zachim est donné pour desloyaux felons et cest l'arbre qui croist au parfont abisme et le fruit est aussi comme teste de deable du quel ilz mengeront et buivront et empliront leurs ventres. (...) L'arbre de Azachim est viande des pecheurs et il s'eschauffe ou ventre comme souffre. Prenez le et portez aux horribles lieux d'enfer.

Quel rapport a cet arbre avec la tradition eschatologique chrétienne? D’un côté, il est évidemment calqué, par antinomie, sur les arbres fruitiers du Paradis. De l'autre, il s'inscrit parfaitement dans l'imaginaire infernal traditionnel qui est fondé sur des images de «dévoration», d'engloutissement. L'image des entrailles, des viscères, est toujours liée à l'idée du tourment. Mais dans les enfers chrétiens les âmes constituent l'objet du repas des bêtes et des démons, alors qu'ici c'est plutôt le contraire : ils doivent avaler des fruits aux têtes de démons qui brûlent leur propre ventre.

\section{L'arbre dans l'œuvre hagiographique de Foulcoie de Beauvais}

\section{Mickaël WILMART}

Né vers 1040 et mort vers 1110, Foulcoie de Beauvais est l'auteur d'une œuvre latine versifiée, d'inspiration religieuse, conséquente. Pendant son séjour 